\title{
ASSESSMENT ON ANTIMICROBIAL PROPERTIES OF SURFACTIN FROM BACILLUS SUBTILIS ON PROTOPLASTS AND SPHEROPLASTS OF PATHOGENIC BACTERIA
}

\author{
B. CHITRA ${ }^{a}$, A. BENNO SUSAI VIJAYAKUMAR
}

aDepartment of Biotechnology, Srimad Andavan Arts and Science College (Autonomous), Trichy-5, Tamil Nadu, India, bepartment of Biochemistry, St. Joseph's College (Autonomous), Trichy-2, Tamil Nadu, India

Email: vijaychithra2006@gmail.com

Received: 25 Sep 2016, Revised and Accepted: 15 Nov 2016

\section{ABSTRACT}

Objective: The aim of this paper is to assessment on antimicrobial properties of surfactin from Bacillus subtilis on protoplasts and spheroplasts of pathogenic bacteria.

Methods: Bacillus sp were isolated from the polluted soil samples and these isolates were screened for biosurfactin activity using haemolytic activity. The biosurfactant was also studied for their antibiotic activity and the minimum inhibitory concentration was determined by testing the effect of surfactin on the pathogenic microorganisms. The lytic activity of surfactant was also tested on the protoplasts and spheroplasts of the pathogens.

Results: The formation of a clear zone around the colonies and the lysis of erythrocytes shows the antimicrobial and lytic activity of biosurfactants.

Conclusion: The results of the current study reveal that surfactin from B. subtilis possesses significant antimicrobial and lytic activity.

Keywords: Soil Sample, Biosurfactant isolation, Protoplast and spheroplast identification and their lytic activity by biosurfactin

(c) 2016 The Authors. Published by Innovare Academic Sciences Pvt Ltd. This is an open access article under the CC BY license (http://creativecommons.org/licenses/by/4.0/)

DOI: http://dx.doi.org/10.22159/ijcpr.2017v9i1.16612

\section{INTRODUCTION}

Pollution caused by crude oil and its products is the most ubiquitous crisis in the environment $[1,2]$. A variety of physical, chemical and biological techniques are used to trim down its negative force on human health, flora and fauna. Bioaugmentation, one of the most resourceful biological techniques, is based on remediation of the unhygienic environment by adding of hydrocarbon degrading microorganisms [3]. Alas, biodegradation of hydrocarbons often is restricted by bioavailability which is connected with their deprived solubility in water and sorption to soil particles. Thus, to boost hydrocarbon bioavailability, synthetic surfactants and biosurfactants are used [4,5]. Biosurfactants have quite a lot of advantages over synthetic surfactants: superior biodegradability, lesser toxicity, high specificity and efficacy at the extreme temperature and $\mathrm{pH}$ values $[3,6]$. The biosurfactants producing microbes are distributed amid a wide variety of genera. For illustration, bacteria that belong to such genera as Bacillus, Pseudomonas, Sphingomonas, Rhodococcus and Arthrobacter [7-12] and yeasts belonging to genera Candida and Yarrowia [13] have been reported to produce surface active compounds. Microorganisms produce the surface active compounds either extracellularly, or these compounds are attached to microbial cells $[6,14]$. In general, their structure includes hydrophilic and hydrophobic moieties. The major classes of biosurfactants include glycolipids (rhamnolipids, trehalolipids, sophrolipids), lipopeptides and lipoproteins, fatty acids, phospholipids, neutral lipids and polymeric biosurfactants $[3,6]$. Biosurfactants often are used in processes of oil removal from contaminated sites and for enhancement of hydrocarbon biodegradation $[2,4,5]$. In some cases, not only biosurfactant itself but also biosurfactant-producing microorganisms are applied for cleaning up of the polluted hydrocarbon environment [15]. Recently, increasing attention has been focused on the hydrocarbon degrading microorganisms with biosurfactant-producing capability [9]. Since these microorganisms are able to produce biosurfactants when grow on hydrocarbon compounds presented in a polluted environment, they are highly promising for bioremediation purposes.

Biosurfactants have gained more importance in the fields of enhanced oil recovery, environmental bioremediation, food processing, and pharma- ceuticals owing to their unique properties higher bio-degradability, lower toxicity, and effectiveness at extremes of temperature, $\mathrm{pH}$ and salinity. Biosurfactants can be produced by microbial fermentation processes using cheaper agro-based substrates and waste materials. In various industrial processes, they are potentially useful surface-active agents for emulsion polymerization, wetting, foaming, phase dispersion, emulsification and de-emulsification [16]. Biosurfactants are mainly categorised mainly by their chemical composition and microbial origin. Generally, their structures include a hydrophilic moiety consisting of amino acids or peptides, mono-di or polysaccharides and a hydrophobic moiety comprising unsaturated or saturate fatty acids. Accordingly, the major classes of biosurfactants include glycolipids, lipopeptides, lipoproteins, phospholipid, fatty acids, polymeric biosurfactant and particulate Biosurfactants [17]. The most prevalent bacterial hydrocarbon degraders and surfactant producers, belong to the genera are Pseudomonas, Achromobacter, Flavobacterium, Micrococcus, Bacillus, Arthrobacter, Klebsiella, Acinetobacter, Aeromonas, Alkaligenes, Streptococcus sp, Corynebacterium sp, Moraxella sp, and proteobacteria [18].

Among the different classes of biosurfactants, surfactin are best-studied subtilin produced by Bacillus subtilis, a gram-positive, motile, rod-shaped bacteria, capable of fermenting sugars like mannitol and glucose, etc. Surfactin is cyclic lipopeptide commonly used as an antibiotic. Surfactin's structure consists of a peptide loop of seven amino acids (L-asparagine, glycine, two L-leucine, L-valine, and two D-Leucins) and an hydrophobic fatty acid chain thirteen to fifteen carbon long [19]. The present study was carried out to determine the antimicrobial activity of the surfactin of B. subtilis and its effect on protoplast and spheroplast of a pathogenic microorganism.

\section{MATERIALS AND METHODS}

\section{Chemicals and reagents}

The chemicals and reagents required for the present study was purchased from High media and were of analytical grade

\section{Isolation of microorganism}

$1 \mathrm{~g}$ of soil sample was collected from polluted sites (petrol bunks, Trichy) and serially diluted for isolation. Different colonies were 
isolated and Bacillus species was identified by its colony morphology. To confirm the culture the following parameters like a physiological test, biochemical test and enzymatic test were observed.

\section{Screening of biosurfactants using the following method \\ Haemolytic activity}

Isolates were screened on blood agar plates containing 5\% sheep blood and incubated at $37{ }^{\circ} \mathrm{C}$ for $48 \mathrm{~h}$. Hemolytic activity was detected as the presence of clear zone around bacterial isolates [20].

\section{Biosurfactant production [21]}

Isolates were grown in $500 \mathrm{ml}$ Erlenmeyer flasks containing $100 \mathrm{ml}$ mineral salt medium adjusted to PH 7.0 was used as culture medium. The flasks were incubated at $37^{\circ} \mathrm{C}$ on a shaker incubator for $7 \mathrm{~d}$. To isolate the biosurfactant, the bacteria were removed by

Centrifugation and the remaining supernatant liquid was filtered through a $0.22 \mathrm{~mm}$ pore size filter (milipore). Biosurfactant was obtained by adjusting the supernatant $\mathrm{PH} 2.0$ using $6 \mathrm{~N} \mathrm{Hcl}$ and keeping it at $4{ }^{\circ} \mathrm{C}$ overnight. The precipitate thus obtained was pelleted by centrifugation for 20 min, dried and weighed. For further purification, the crude surfactant was dissolved in distilled water at PH 7.0 and dried at $60^{\circ} \mathrm{C}$. The dry product was extracted with chloroform: methanol (65:15) filtered and the solvent evaporated.

\section{Antibiotic activity of surfactin}

The biosurfactant was also studied for their antibiotic activity. The effect of surfactin on some microorganisms is detected by Kirby-Bauer disc diffusion method. The medium (Muller-Hinton agar) was prepared and poured into the sterile Petri plates aseptically. After solidification, the microorganisms were inoculated on the medium by spreading the inoculums of the medium with a sterile swab. Filter paper discs were sterilized and impregnated with biosurfactant. Then the discs were placed on the surface of the agar plate seeded with the test organisms. Finally, the plates were incubated at $30^{\circ} \mathrm{C}$ for $24-48 \mathrm{~h}$. The size of the zone of inhibition caused by the diffusion of the agent into the agar is directly related to the degree of susceptibility of gram positive and gram negative bacteria to biosurfactant produced by Bacillus subtilis.

\section{Concentration method}

The antimicrobial activity of the surfactin was determined and the minimum inhibitory concentration was determined by testing the effect of surfactin on the pathogenic microorganisms. For $100 \%$ concentration, the extracted surfactin was used as such, and $25 \%$ and $50 \%$ concentrations were prepared using distilled water. Then the Muller-Hintan agar was prepared, and the discs impregnated with various concentrations of surfactin were placed on the medium seeded with the organism. The plates were incubated at $37^{\circ} \mathrm{C}$ for 24 to $48 \mathrm{~h}$. the results were recorded and tabulated.

\section{Isolation of protoplast}

The protoplast was isolated from the gram-positive bacterial cell culture. The bacterial pellet obtained after centrifugation is taken out into a hypotonic sucrose solution which provides the osmotic pressure to the fluid in the milieu, exterior so thast it exerts a gentle osmotic gradient and thus prevents immediate vigorous lysis of the protoplasts formed by the action of lysozyme.

Bacterial culture was grown in nutrient broth overnight and centrifuged at $7000 \mathrm{rpm}$ for $5 \mathrm{~min}$ and harvested. The harvested pellet was taken into $1 \mathrm{ml}$ hypotonic solution of $0.5 \mathrm{M}$ sucrose solution. Lysozyme at a concentration of 0.1 to $1 \mathrm{mg} / \mathrm{ml}$ was added to this sucrose solution. It was kept for $30 \mathrm{~min}$ for digestion. Lysozyme digestion can be carried out in the cold or at room temperature. After digestion, protoplast formation was observed under phase contrast microscope.

\section{Isolation of spheroplast}

The spheroplast was isolated from the gram negative bacterial cell culture. Bacterial pellet collected after centrifugation were resuspended in sucrose solution and in Tris-acetate buffer. This provides the osmotic pressure to the fluid in the milleu exterior so that it exerts a gentle osmotic gradient and thus prevents immediate vigorous lysis of the spheroplast formed by the action of lysozyme and EDTA. Lysozyme dissolves peptidoglycan exposed by the disruption of the outer membrane surrounding the cell wall of the bacteria leading to the formation of spheroplasts. In addition after lysozyme treatment, the suspension was slowly diluted with EDTA which disrupts the outer membrane and allows lysozyme to reach and degrade the rigid mucopeptide layer so that the spheroplasts were formed.

Bacterial culture was grown in nutrient broth overnight and centrifuged at $7000 \mathrm{rpm}$ for $5 \mathrm{~min}$ and harvested. The harvested pellets were resuspended in $1 / 10$ th of the cultures volume in 0.75 mmol Sucrose, in $10 \mathrm{mmol}$ Tris-acetate buffer of $\mathrm{pH}$ 7.8. Lysozyme was added to give the final concentration of $0.1 \mathrm{mg} / \mathrm{ml}$ and the suspension was incubated in ice for $2 \mathrm{~min}$. Now conversion of spheroplasts was accompanied by the slow dilution of the suspension over a period of 3$10 \mathrm{~min}$ by the addition of 2 volumes of $1.5 \mathrm{mmol}$ EDTA. The suspension was gently agitated during the dilution period, and conversion to spheroplast was observed under phase contrast microscope.

\section{Effect of surfactin on protoplasts and spheroplasts}

The protoplasts and spheroplasts were induced in the pathogens and the effect of surfactin on them was tested. About $1 \mu \mathrm{l}$ per $\mathrm{ml}$ of surfactin was added, and the effect was determined.

The effect of surfactin on protoplasts and spheroplasts was tested on broth medium by the following procedure. About $5 \mathrm{ml}$ of the medium was poured into each test tube (in about 12 test tubes) and sterilised in an autoclave at $15 \mathrm{lb}$ for $15 \mathrm{~min}$. After cooling the medium, the spheroplast was induced in E. coli., S. typhi and $P$. aeuroginosa by adding $1 \mathrm{ml}$ of $0.75 \mathrm{mmol}$ Sucrose, $10 \mathrm{mmol}$ EDTA solution were added. The protoplasts were induced in S. aureus and $S$. faecalis by adding $1 \mathrm{ml}$ of $0.5 \mathrm{M}$ sucrose solution and lysozyme to the medium. Along with that about $1 \mu \mathrm{l}$ per $\mathrm{ml}$ of surfactin was added to the medium for determining the lysing activity of surfactin on protoplasts and spheroplasts.

\section{RESULTS AND DISCUSSION}

The bacterium was a gram positive rod shaped organism capable of fermenting sugars like mannitol and glucose etc., The bacterium isolated was Bacillus subtilis and confirmed with reference to Bergey's manual of determinative bacteriology. The surfactin produced by Bacillus subtilis inhibits clot formation, lyses erythrocytes, a bacterial spheroplast and protoplasts, etc., The surfactin was produced in glucose mineral salt medium and extracted by acid precipitation. The bacteria Blood agar method is often used for a preliminary screening of microorganisms for the ability to produce biosurfactants on hydrophilic media [22]. The ability of the bacterium to produce biosurfactant was tested on blood agar medium, and the clear zone formation around the colonies shows the production of biosurfactant and lysis of erythrocytes. The lysis of erythrocytes by surfactin was confirmed by microscopic observation (Plate.1-3). This result correlates with the findings of [23] and [24]. The effect of surfactin on various pathogens was tested at various concentrations. For $100 \%$ concentration, the extracted surfactin is used as such and from that $25 \%$ and $50 \%$ concentrations were prepared and tested. The surfactin was found to be slightly inhibitory for Staphylococus aureus at $25 \%$ concentration. At $50 \%$ concentration, the surfactin was inhibitory for Streptococcus faecalis, Pseudomonas aeruginosa and E. coli whereas the organism Salmonella typhi was found to be sensitive against surfactin only at $100 \%$ concentration [Graph 1].

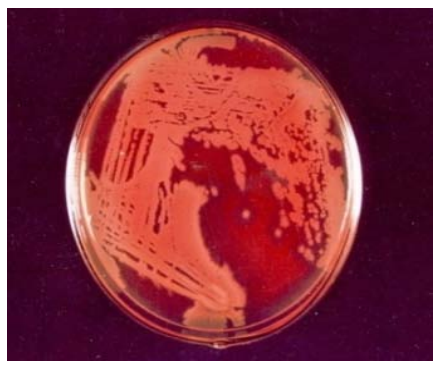

Plate 1: Lysis of RBC's by surfactin on culture 


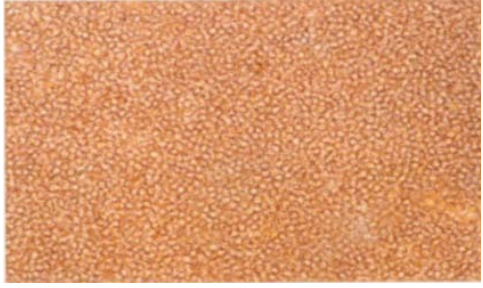

Plate 2: Native RBC's

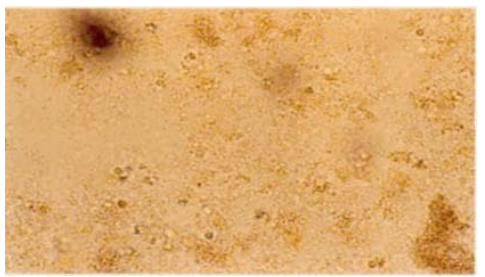

Plate 3: RBC's cells lysed by surfactin

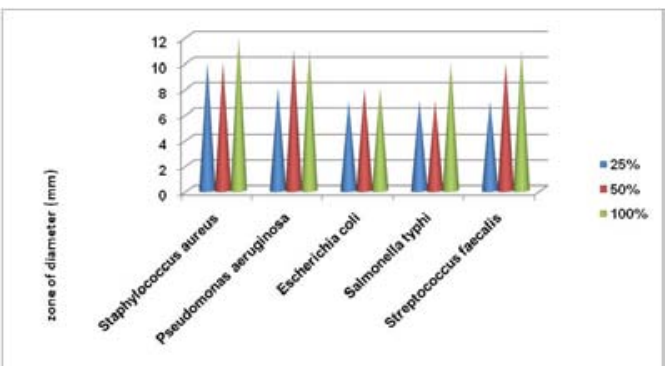

Graph 1: Effect of surfactin At different concentration on pathogenic bacteria

Lysozyme is an enzyme which dissolves the peptidoglycan forming the cell wall of the bacterium leading to the formation of protoplasts. The protoplasts of gram positive organism and spheroplasts of gramnegative organisms were induced and surfactin was tested on them for identifying the activity of surfactin on protoplasts and spheroplasts. The results showed that the surfactin has the microbicidal activity and it even kills the bacterial spheroplast and protoplast in adverse hypotonic and hypertonic conditions. These characters of surfactin can be used for various applications and in the pharmaceutical industries for creating a new antimicrobial agent.

\section{CONCLUSION}

From the above observation, it was concluded that the bacterial isolates of Bacillus have the ability to secrete surface active agents. Thus apart from industrial applications they can also be used for medicinal purposes and has a wide scope in pharmaceutical industries. It gains on more important in future for industrial and environmental applications.

\section{CONFLICT OF INTERESTS}

\section{Declare none}

\section{REFERENCES}

1. Caprino L, Togna GJ. Potential health effects of gasoline and its constituents. Environ Health Perspect 1998;106:115-25.

2. Millioli VS, Servulo ELC, Sobral LGS, de Carvalho DD. Bioremediation of crude oil-bearing soil: evaluating the effect of rhamnolipid addition to soil toxicity and to crude oil biodegradation efficiency. Global Nest J 2009;11:181-8.

3. Kosaric N. Biosurfactants and their application for soil bioremediation. Food Technol Biotechnol 2001;39:295-304.

4. Guo-liang Z, Yue-ting W, Xin-ping Q, Qin M. Biodegradation of crude oil by Pseudomonas aeruginosa in the presence of rhamnolipids. J Zhejiang Univ Sci 2005;8:725-30.
5. Youssef N, Simpson DR, Duncan KE, McInerney MJ, Folmsbee M, Fincher $\mathrm{T}$, et al. In situ biosurfactant production by Bacillus strains injected into a limestone petroleum reservoir. Appl Environ Microbiol 2007;73:1239-47.

6. Gautam KK, Tyagi VK. Microbial surfactants: a review. J Oleo Sci 2006;55:155-66.

7. Suwansukho P, Rukachisirikul V, Kawai F, H-Kittikun A Production and applications of biosurfactant from Bacillus subtilis MUV4. Songklanakarin J Sci Technol 2008;30:87-93.

8. Makkar RS, Cameotra SS. Effects of various nutritional supplements on biosurfactant production by a strain of Bacillus subtilis at $45^{\circ} \mathrm{C}$. J Surfactants Deterg 2002;5:11-7.

9. Das K, Mukherjee AK. Crude petroleum-oil biodegradation efficiency of Bacillus subtilis and Pseudomonas aeruginosa strains isolated from a petroleum-oil contaminated soil from North-East India. Bioresour Technol 2007;98:1339-45.

10. Bredholt H, Josefsen K, Vatland A, Bruheim P, Eimhjellen K. Emulsification of crude oil by an alkane-oxidizing Rhodococcus species isolated from seawater. Canadian J Microbiol 1998;44:330-40.

11. Morikawa M, Daido H, Takao T, Satoru M, Shimonishi Y, Imanaka T. A new lipopeptide biosurfactant produced by Arthrobacter sp. strain MIS38. J Bacteriol 1993;175:6459-66.

12. Pruthi V, Cameotra SS. Short communication: production and properties of a biosurfactant synthesised by Arthrobacter protophormiae-an antarctic strain. World J Microbiol Biotechnol 1997;13:137-39.

13. Amaral PFF, Coelho MAZ, Marrucho IM, Coutinho JAP. Biosurfactants from yeasts: characteristics, production and application. In: Biosurfactants. Sen R. ed. Springler Sience; 2010. p. 236-49.

14. Maneerat S, Dikit P. Characterization of cell-associated bioemulsifier from Myroides sp. SM1, a marine bacterium. Songklanakarin J Sci Technol 2007;29:769-79.

15. Kumar M, Leon V, de Sisto Materano A, Ilzins OA. Enhancement of oil degradation by co-culture of hydrocarbon degrading and biosurfactant producing bacteria. Polish J Microbiol 2006;55:139-46.

16. Desai JD, Banat IM. Microbial production of surfactants and their commercial potencial. Microbiol Mol Biol 1997;61:47-64.

17. Maneerat S. Biosurfactants from marine microorganisms. Songklanakarin J Sci Technol 2005;27:1263-1272.

18. Mishra SJ, Jyot RC, Kuhad B. Evaluation of inoculums addition to stimulate in situ bioremediation of oily sludge contaminated soil. Appl Environ Microbiol 2001;6 Suppl 4:1675-81.

19. Peypoux F, Bonmatin JM, Wallach J. Recent trends in the biochemistry of surfactin. Appl Microbiol Biotechnol 1999; 51:553-63.

20. Plaza GA, Zjawiony I, Banat IM. Use of different methods for detection of thermophilic biosurfactant producing bacteria from hydrocarbon-contaminated and bioremediating soils. J Petroleum Sci Eng 2006;50:71-7.

21. Pornsunthorntawee O, Rttaweeporn N, Paisanjit S, Somboonthanate $\mathrm{M}$, Abe Rujiravanit $\mathrm{R}$, Chavadej $\mathrm{S}$. Isolation and comparison of biosurfactants produced by Bacillus subtilis and Pseudomonas aeruginosa SP4 for microbial surfactant enhanced oil recovery. Biochem Eng J 2008;42:172-9.

22. Schulz D, Passeri A, Schmidt M. Screening for biosurfactants among crude oil degrading marine microorganisms from the North-sea. Naturforsch 1991;46 Suppl 4:197-203.

23. Bernheimer AW, Avigad LS. Nature and properties of a cytolytic agent produced by Bacillus subtilis. J Gen Microbiol 1970;61:361-9.

24. Cooper DG, MacDonald CR, Duff SJB, Kosaric N. Enhanced production of surfactin from B. subtilis by continuous product removal and metal cation additions. Appl Environ Microbiol 1981;42:408-12.

\section{How to cite this article}

- B Chitra, A Benno Susai Vijayakumar. Assessment on antimicrobial properties of surfactin from Bacillus subtilis on protoplasts and spheroplasts of pathogenic bacteria. Int J Curr Pharm Res 2017;9(1):67-69. 